ARTICLE

\title{
Discovery of abnormal lithium-storage sites in molybdenum dioxide electrodes
}

Jeong Kuk Shon ${ }^{1,2}$, Hyo Sug Lee, Gwi Ok Park ${ }^{2,3}$, Jeongbae Yoon ${ }^{3}$, Eunjun Park ${ }^{4}$, Gyeong Su Park ${ }^{1}$, Soo Sung Kong ${ }^{2}$, Mingshi Jin ${ }^{5}$, Jae-Man Choi ${ }^{1}$, Hyuk Chang ${ }^{1}$, Seokgwang Doo ${ }^{1}$, Ji Man Kim²,3, Won-Sub Yoon ${ }^{3}$, Chanho Pak ${ }^{6, *}$, Hansu Kim ${ }^{4} \&$ Galen D. Stucky ${ }^{7, \star}$

Developing electrode materials with high-energy densities is important for the development of lithium-ion batteries. Here, we demonstrate a mesoporous molybdenum dioxide material with abnormal lithium-storage sites, which exhibits a discharge capacity of $1,814 \mathrm{mAh}^{-1}$ for the first cycle, more than twice its theoretical value, and maintains its initial capacity after 50 cycles. Contrary to previous reports, we find that a mechanism for the high and reversible lithium-storage capacity of the mesoporous molybdenum dioxide electrode is not based on a conversion reaction. Insight into the electrochemical results, obtained by in situ X-ray absorption, scanning transmission electron microscopy analysis combined with electron energy loss spectroscopy and computational modelling indicates that the nanoscale pore engineering of this transition metal oxide enables an unexpected electrochemical mass storage reaction mechanism, and may provide a strategy for the design of cation storage materials for battery systems.

\footnotetext{
${ }^{1}$ Samsung Advanced Institute of Technology, Samsung Electronics Co., Ltd., Suwon 443-803, Republic of Korea. ${ }^{2}$ Department of Chemistry, Sungkyunkwan University, Suwon 440-746, Republic of Korea. ${ }^{3}$ Department of Energy Science, Sungkyunkwan University, Suwon 440-746, Republic of Korea.

${ }^{4}$ Department of Energy Engineering, Hanyang University, Seoul 133-791, Republic of Korea. ${ }^{5}$ Key Laboratory of Natural Resource of the Changbai Mountain and Functional Molecular (Yanbian University), Ministry of Education, Department of Chemistry, Park Road 977, Yanji City, Jilin Province 133002, China. ${ }^{6}$ Fuel Cell Group, Corporate R\&D Center, Samsung SDI Co., Ltd., Yongin 446-577, Republic of Korea. ${ }^{7}$ Department of Chemistry and Biochemistry, University of California, Santa Barbara, California 93106, USA. *These authors jointly supervised this work. Correspondence and requests for materials should be addressed to J.M.K. (email: jimankim@skku.edu) or to W.-S.Y. (email: wsyoon@skku.edu) or to H.K. (email: khansu@hanyang.ac.kr).
} 
ithium (Li)-ion batteries (LIBs) are a key-enabling technology for addressing the power and energy demands of electric vehicles and stationary electrical storage for renewable energy as well as mobile electronics ${ }^{1}$. However, the energy density of currently commercialized LIBs is already close to its technological limit $^{2}$. In order to achieve the battery performance that all applications expect, much effort has been made to develop new electrode materials to improve both the energy density and cycle performance of $\mathrm{LIBs}^{3}$. The main goal of these research efforts are to enable energy densities that are higher than the theoretical limit predicted for current Li-ion intercalation batteries. These new batteries would have the desired physicochemical properties, especially high reversible capacity, structural flexibility and stability, high rate capability, low cost and environmental benignity ${ }^{4,5}$. In order to improve the performance of anode parts replacing graphite (theoretical capacity of $372 \mathrm{mAhg}^{-1}$ ), there has been extensive research on developing anode materials such as transition metal oxides, silicon- or tinbased metal alloys, and related composite configurations ${ }^{3-11}$. Since they follow Li-storage mechanisms such as conversion and alloying reactions with $\mathrm{Li}$, which are different from the $\mathrm{Li}$ intercalation reaction in the graphite anode, these newly developed anode materials show higher capacity than the current anode systems. In particular, there had been several reports that some transition metal oxides showed the reversible capacity exceeding their theoretical capacity based on the conversion reaction. This abnormal capacity of transition metal oxides has been explained by various mechanisms based on the interfacial reaction: (i) reversible formation/dissolution of organic film at the interface between the electrolyte and the transition metal oxide $^{9,12}$; (ii) interfacial charge storage between metal nanocrystals and $\mathrm{Li}$ salts ${ }^{13,14}$; and (iii) generation of $\mathrm{LiOH}$ on the surface of metal oxide and subsequent reversible reaction between $\mathrm{LiOH}$ and $\mathrm{Li}^{15}$. Hence, even though the origins of extra capacity of transition metal oxides are different from each other, one of the effective approaches is nano-engineering of transition metal oxides for LIBs ${ }^{16-18}$. This approach has the potential to significantly increase the reversible capacity and the rate capability of anode materials by enlarging the interfacial area between the electrode and electrolyte. It is also expected that nanostructured transition metal oxides should show much improved cycle performance by providing the mechanical/structural integrity against huge changes in volume and crystal structure.

Mesoporous materials are excellent nanoscale-engineered candidates for numerous applications because of their high surface areas, tunable pore sizes, adjustable framework thickness and compositions, and diverse surface properties ${ }^{19-23}$. Recently, various novel mesoporous metal oxides have been widely investigated as electrode materials for $\mathrm{LIBs}^{24-28}$. These studies have opened up a possibility for the development of anode materials with significantly improved Li-storage performance. The mesostructure can be readily designed to exhibit hierarchical mesoporosity to promote facile and fast Li-ion diffusion, and a uniform framework thickness of $10 \mathrm{~nm}$ or less so that there is a reduced diffusion length for solid-state Li transport. Interestingly, we have found that the mesoporous $\mathrm{MoO}_{2}$ anode presented here gives a high Li-storage capacity $\left(1,814 \mathrm{mAhg}^{-1}\right.$ at first cycle and $1,607 \mathrm{mAhg}^{-1}$ after 50 cycles), which is much higher than its theoretical capacity based on the conversion reaction of $\mathrm{MoO}_{2}$ with $\mathrm{Li}\left(838 \mathrm{mAhg}^{-1}\right)$. As aforementioned, several research groups have newly proposed Li-storage mechanisms ${ }^{12-15,29}$; however, this extra Li-storage mechanism of transition metal oxide is still unclear, suggesting that the high capacity of the mesoporous $\mathrm{MoO}_{2}$ in the present work probably results from a different Li-storage mechanism than those previously reported ${ }^{12-15}$.
Here we report a mechanism for the high and reversible Li-storage capacity of the mesoporous $\mathrm{MoO}_{2}$ anode based on various physicochemical analyses and computational modelling. To the best of our knowledge, this is the first demonstration of a Li-storage oxide anode material that utilizes two different Li-storage mechanisms composed of both a Li-ion intercalation and a metallic Li storage. This enables a structural and electronic configuration that is, in a sense, a hybrid between the $\mathrm{Li}$ intercalation compound anode and the metallic $\mathrm{Li}$ anode, with the inherent safety features of the former and energy density approaching that of the latter. We believe that understanding the origin and mechanism of this excellent performance will enable important advances in the design and creation of high-energy storage devices.

\section{Results}

Li-storage characteristics of mesoporous $\mathrm{MoO}_{2}$. The mesoporous $\mathrm{MoO}_{2}$ material, which exhibits regular mesopores $(18.2 \mathrm{~nm}$ in diameter), highly crystalline frameworks ( $\sim 7 \mathrm{~nm}$ thickness) and high surface areas of $115 \mathrm{~m}^{2} \mathrm{~g}^{-1}$, was successfully obtained from a mesoporous silica template (Fig. la-f and Supplementary Fig. 1). Electrochemical performances of the mesoporous $\mathrm{MoO}_{2}$ electrode and a bulk $\mathrm{MoO}_{2}$ (Aldrich, $S_{\mathrm{BET}}=0.23 \mathrm{~m}^{2} \mathrm{~g}^{-1}$ ) electrode are shown in Fig. 1g,h. There is an obvious difference in the Li-storage behaviours of the mesoporous $\mathrm{MoO}_{2}$ and bulk $\mathrm{MoO}_{2}$ electrodes. For the bulk $\mathrm{MoO}_{2}$ electrode, the discharge (Li insertion) and charge (Li removal) capacities are 385 and $183 \mathrm{mAhg}^{-1}$ (for the first cycle), respectively, indicating that $1.84 \mathrm{~mol}$ of $\mathrm{Li}$ per mol of $\mathrm{MoO}_{2}$ can be stored into bulk $\mathrm{MoO}_{2}$, and $0.87 \mathrm{~mol}$ of $\mathrm{Li}$ are reversibly released from the lithiated bulk $\mathrm{MoO}_{2}$. On the other hand, the mesoporous $\mathrm{MoO}_{2}$ delivered a reversible charge capacity of $1,308 \mathrm{mAhg}^{-1}$ (for the first cycle) with an initial coulombic efficiency of $72.1 \%$ (discharge capacity of $1,814 \mathrm{mAhg}^{-1}$ ), which is much higher than those of the bulk $\mathrm{MoO}_{2}$ electrode and corresponds to the reversible removal of $6.24 \mathrm{~mol}$ of $\mathrm{Li}$ per $\mathrm{mol}$ of $\mathrm{MoO}_{2}$ from the fully lithiated mesoporous $\mathrm{MoO}_{2}$. More importantly, the reversible Li-storage capacity of mesoporous $\mathrm{MoO}_{2}(6.24 \mathrm{~mol}$ of $\mathrm{Li}$ per mol of $\mathrm{MoO}_{2}$ ) at the first cycle exceeds the theoretical limit of Li-storage capacity through conversion reaction of $\mathrm{MoO}_{2}$ with $\mathrm{Li}$ ( $4 \mathrm{~mol}$ of $\mathrm{Li}$ per mol of $\mathrm{MoO}_{2}$ ), suggesting that a new Li-storage mechanism should be introduced to explain this unexpected Li-storage performance.

As shown in Fig. 1i,j, Supplementary Figs 2 and 3 and Supplementary Table 1, the Li-storage capacities of the $\mathrm{MoO}_{2}$ electrodes are linearly correlated with their surface areas, even though the shapes in the small-angle X-ray diffraction (XRD) patterns and $\mathrm{N}_{2}$ sorption isotherms of mesoporous $\mathrm{MoO}_{2}$ materials areas are very similar (Supplementary Figs 4 and 5). In the case of mesoporous $\mathrm{MoO}_{2}$ with surface area of $39 \mathrm{~m}^{2} \mathrm{~g}^{-1}$, the first and tenth reversible charge capacities are only $422 \mathrm{mAhg}^{-1}$ (discharge capacity of $1,022 \mathrm{mAhg}^{-1}$ ) and $814 \mathrm{mAh}^{-1}$, respectively, which are much lower than those of the mesoporous $\mathrm{MoO}_{2}$ with surface area of $115 \mathrm{~m}^{2} \mathrm{~g}^{-1}(1,308$ and $1,594 \mathrm{mAhg}^{-1}$, respectively). This result clearly indicates that the quality of the nanostructure of the mesoporous $\mathrm{MoO}_{2}$ material is very crucial to achieve a high Li-storage capacity that exceeds the theoretical value. Differences in the synthesis of mesoporous $\mathrm{MoO}_{2}$ materials with low and high surface areas are described in the Methods section. For more insight, scanning electron microscopic (SEM) images were obtained for the mesoporous $\mathrm{MoO}_{2}$ materials with different surface areas (Supplementary Fig. 6). Interestingly, there are co-existing large particles in the cases of the low surface area materials (39 and $76 \mathrm{~m}^{2} \mathrm{~g}^{-1}$; Supplementary Fig. 6c,e), whereas entire 

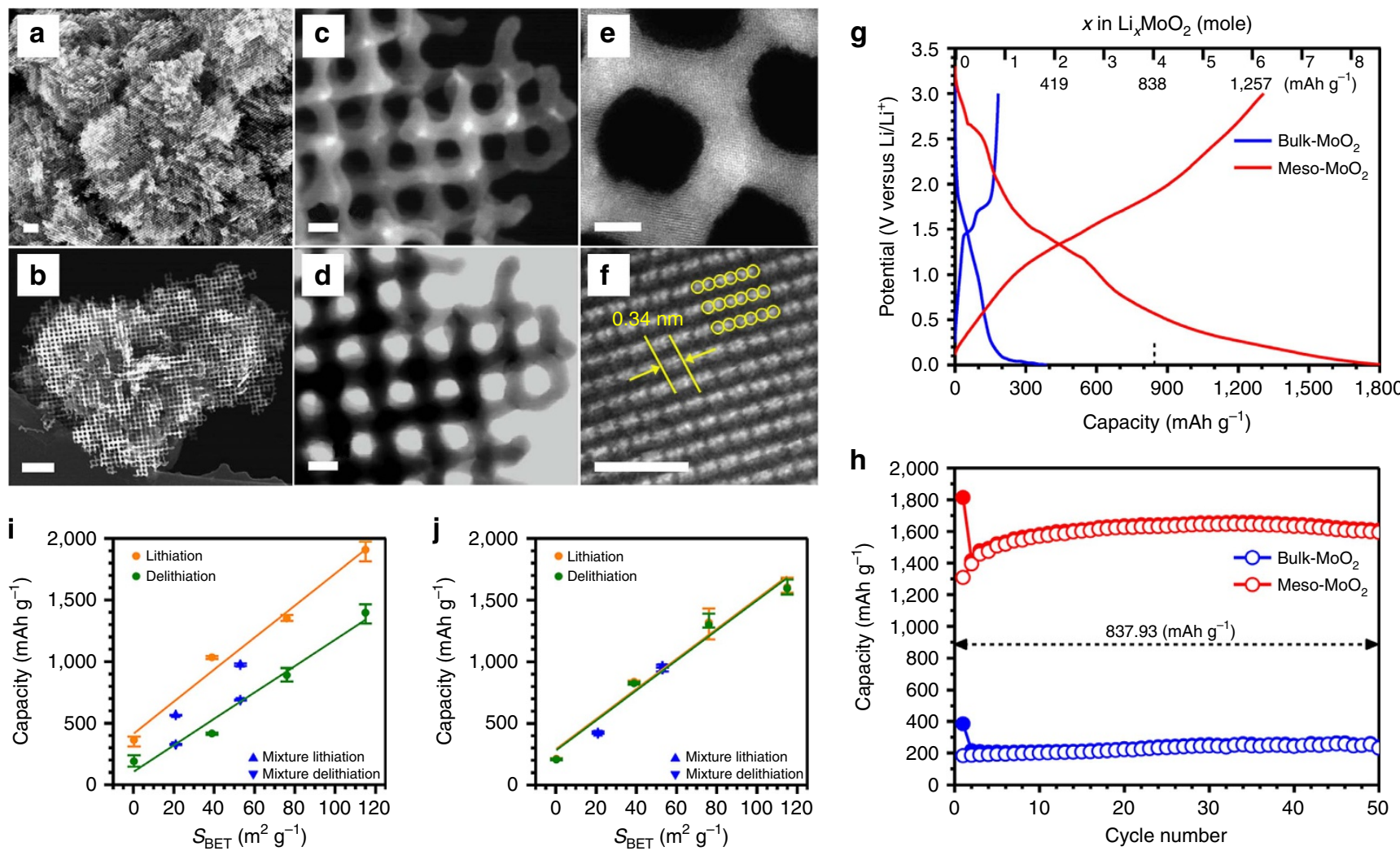

Figure 1 | Ordered mesoporous $\mathbf{M o O}_{\mathbf{2}}$ and Li-storage performance. (a,b) SEM, (c,e) STEM, (d) TEM and (f) HRTEM images of ordered mesoporous $\mathrm{MoO}_{2}$ materials. Electrochemical performance of ordered mesoporous $\mathrm{MoO}_{2}\left(\mathrm{~S}_{\mathrm{BET}}=115 \mathrm{~m}^{2} \mathrm{~g}^{-1}\right)$ and bulk $\mathrm{MoO}_{2}\left(\right.$ Aldrich, $\left.\mathrm{S}_{\mathrm{BET}}=0.23 \mathrm{~m}^{2} \mathrm{~g}-1\right)$ : $(\mathbf{g})$ voltage profiles and $(\mathbf{h})$ cycle performances at current rate of $0.1 \mathrm{C}$ in $1.3 \mathrm{M} \mathrm{LiPF}_{6}$ (ethylene carbonate/diethyl carbonate $(\mathrm{EC} / \mathrm{DEC})=3 / 7$, by volume ratio). The value $\left(837.93 \mathrm{mAh}^{-1}\right.$ ) represents the theoretical capacity for $\mathrm{MoO}_{2}$, based on conversion reaction ( $4 \mathrm{~mol}$ of $\mathrm{Li}$ per $1 \mathrm{~mol}$ of $\mathrm{MoO}_{2}$ ).

Relationship of the Li-storage capacities of the $\mathrm{MoO}_{2}$ electrodes with respective to their surface areas: (i) the first and (j) the tenth lithiation/delithiation. The galvanostatic lithiation/delithiation tests were replicated for three times. Error bars $(\mathbf{i}, \mathbf{j})$ represent the standard deviation of the mean about a series of the measured values. Straight line is a linear fit. Scale bars $=100 \mathrm{~nm}(\mathbf{a}, \mathbf{b}), 10 \mathrm{~nm}(\mathbf{c}, \mathbf{d}), 5 \mathrm{~nm}(\mathbf{e})$ and $1.5 \mathrm{~nm}(\mathbf{f})$.

particles of the mesoporous $\mathrm{MoO}_{2}$ with the surface area of $115 \mathrm{~m}^{2} \mathrm{~g}^{-1}$ exhibit highly ordered mesostructures (Fig. 1a and Supplementary Fig. 6f). For comparison, the Li-storage behaviours of two different mixtures of bulk $\mathrm{MoO}_{2}$ and highquality mesoporous $\mathrm{MoO}_{2}$ materials (resulting in $S_{\mathrm{BET}}=21$ $\mathrm{m}^{2} \mathrm{~g}^{-1}$ and $53 \mathrm{~m}^{2} \mathrm{~g}^{-1}$, respectively; Supplementary Figs 4,5 and $6 \mathrm{~b}, \mathrm{~d}$ and Supplementary Table 1) were also investigated, indicating that the mixtures give similar trends of Li-storage capacities depending on their surface areas.

In order to gain insight on the physics and material science of $\mathrm{Li}$ storage in the present ordered mesoporous $\mathrm{MoO}_{2}$, we performed ex situ XRD analyses during the lithiation and delithiation of the ordered mesoporous $\mathrm{MoO}_{2}$. Figure 2a shows that Bragg peaks corresponding to $\mathrm{MoO}_{2}$ phase shifted to lower angles with an increase in the amount of $\mathrm{Li}$ stored, and returned to their initial scattering angles during the delithiation step, indicating highly reversible $\mathrm{Li}$ intercalation of the $\mathrm{MoO}_{2}$ host without collapse of its crystalline structure during cycling. High-resolution transmission electron microscopic (HRTEM) images (Fig. 2b) also show reversible changes of crystalline structure during the first cycle. We also observed reversible shifts of the Bragg peaks of $\mathrm{MoO}_{2}$ without the breakdown of the crystal structure even during the second cycle (Supplementary Fig. 7). It should be noted that we could not detect the evolution of any other phase related to the conversion reaction of $\mathrm{MoO}_{2}$, such as metallic $\mathrm{Mo}$ and $\mathrm{Li}_{2} \mathrm{O}$, even after lithiation was electrochemically completed. These ex situ XRD analyses suggest that the present ordered mesoporous $\mathrm{MoO}_{2}$ does not follow the conventional conversion reaction mechanism, in which there is accommodation and release of $\mathrm{Li}$ ions by a $\mathrm{Li}$ intercalation mechanism. The XRD patterns obtained after the full lithiation $\left(\mathrm{D}-0.0 \mathrm{~V}\right.$ in Fig. $2 \mathrm{a},>7 \mathrm{~mol}$ of $\mathrm{Li}$ per $1 \mathrm{~mol}$ of $\left.\mathrm{MoO}_{2}\right)$ are very similar to the monoclinic $\mathrm{Li}_{x} \mathrm{MoO}_{2}$ phase, which means that the phase transition of crystal structures during the cycle is not the key for the unexpected high Li-storage capacity of the present mesoporous $\mathrm{MoO}_{2}$ material. In the HRTEM images (Supplementary Fig. 8), we found that the highly crystalline framework of the pristine mesoporous $\mathrm{MoO}_{2}$ material became a mixture of crystalline phase and amorphous phase upon the lithiation. This suggests that the amorphous phases formed between the crystalline domains may be critical for such high capacity of mesoporous $\mathrm{MoO}_{2}$. In situ Mo K-edge X-ray absorption near edge structure (XANES; Fig. $2 \mathrm{c}$ and Supplementary Fig. 9) spectra for the ordered mesoporous $\mathrm{MoO}_{2}$ electrode during lithiation show a clear shift of the absorption edge towards lower energy position, showing a change in the electronic structure of molybdenum from $\mathrm{Mo}^{4+}$ to a formal oxidation state close to $\mathrm{Mo}^{1+}$. This result indicates formation of another domain (probably the amorphous phase shown in the HRTEM image; Supplementary Fig. 8), in addition to the Li-intercalated monoclinic $\mathrm{Li}_{x} \mathrm{MoO}_{2}$ phase during the lithiation. Furthermore, in situ Mo K-edge extended X-ray absorption fine structure (EXAFS; Fig. 2d) spectra for the ordered mesoporous $\mathrm{MoO}_{2}$ show that the Mo-O and Mo-Mo peaks in the EXAFS spectra correspond to the coordination shells in $\mathrm{MoO}_{2}$ structure, excluding any possibility of metallic Mo phase. Besides the extraordinarily high capacity, these contradictory XANES and EXAFS results against the conventional conversion 

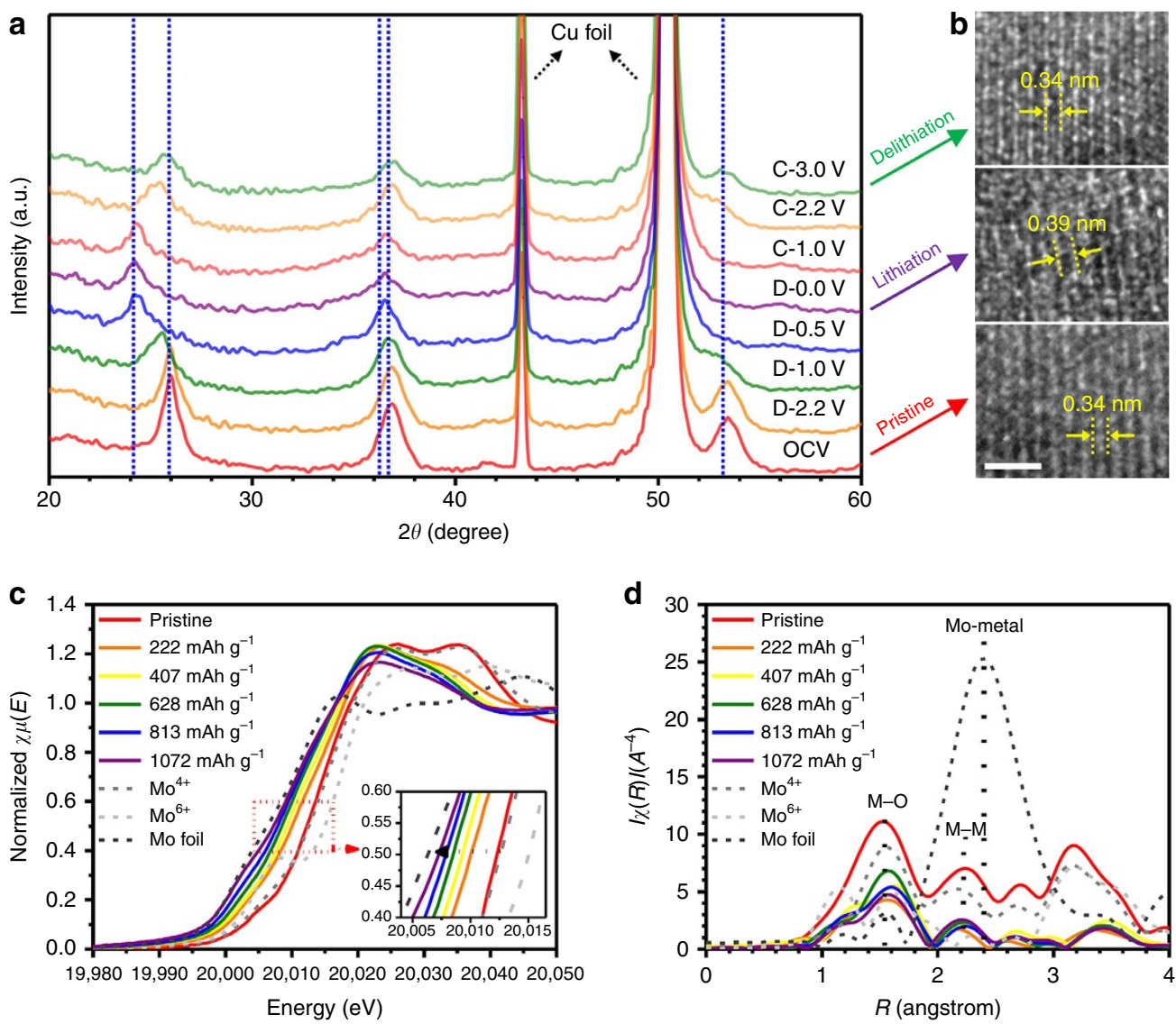

Figure 2 | Structure evolution of Li storage in ordered mesoporous $\mathbf{M o O}_{\mathbf{2}}$. (a) Ex situ XRD patterns of ordered mesoporous $\mathrm{MoO}_{2}$ during the first cycle as a function of depth of discharge and charge. (b) HRTEM images of mesoporous $\mathrm{MoO}_{2}$ before lithiation, after full lithiation and after full delithiation. Scale bar $=1.5 \mathrm{~nm}$. (c) In situ XANES patterns and (d) in situ EXAFS patterns of ordered mesoporous $\mathrm{MoO}_{2}$ electrode for the first lithiation.

reaction of transition metal oxide anode materials strongly suggest that another reaction model for $\mathrm{Li}$ storage into the ordered mesoporous $\mathrm{MoO}_{2}$ should be considered in order to understand the origin of the extraordinary high Li-storage properties and the electrochemical reaction mechanism of the ordered mesoporous $\mathrm{MoO}_{2}$ with $\mathrm{Li}$.

Mechanism study on the Li-storage sites. In order to obtain a theoretical perspective into the atomic movement and redox behaviour that occur upon lithiation of $\mathrm{MoO}_{2}$, we performed density functional theory (DFT) calculations on the Li-storage mechanism of the ordered mesoporous $\mathrm{MoO}_{2}$. Figure 3a shows that the lithiation process of $\mathrm{MoO}_{2}$ is almost the same for $\mathrm{Li}$ intercalation up to $\mathrm{Li}_{1.5} \mathrm{MoO}_{2}$ as evident from the small increase in unit cell volume $(\sim 20 \%)$ and the retention of initial crystal structure, that is, the monoclinic $\mathrm{MoO}_{2}$ phase. However, further $\mathrm{Li}$ storage leads to phase separation of the lithiated $\mathrm{MoO}_{2}$ into a Li-rich phase (the amorphous domain in Supplementary Fig. 8) and $\mathrm{Li}$-intercalated $\mathrm{MoO}_{2}$ crystalline phase (the crystalline domain in Supplementary Fig. 8). During the initial stage of this phase separation of lithiated $\mathrm{MoO}_{2}$, we found that additional $\mathrm{Li}$ atoms are deposited as nearest neighbours to a position occupied by a former $\mathrm{Li}$ atom. This near-neighbour $\mathrm{Li}$ atom siting is more energetically favourable as a new position for a $\mathrm{Li}$ atom than is a random position (Supplementary Fig. 10). As shown in Fig. 3a, the further lithiation results in volume increase during cycling without expansion in the lithiated crystalline $\mathrm{Li}_{1.5} \mathrm{MoO}_{2}$ domain. This total volume expansion by formation of $\mathrm{Li}$-rich phase is probably an important characteristic that enables efficient $\mathrm{Li}$ storage in the ordered mesoporous $\mathrm{MoO}_{2}$. With an increase in the depth of the lithiation layer, only the Li-rich phase (formed between crystalline $\mathrm{Li}_{x} \mathrm{MoO}_{2}$ domains) reacts with $\mathrm{Li}$ ion, and the interatomic distance between $\mathrm{Li}$ atoms tends to decrease, suggesting that the electronic structure of the Li atoms turns into a metallic state. As seen in Supplementary Fig. 11, the calculated partial density of state of Li $s$-band clearly shows the change of the electronic states of Li into metallic states when $x>1.5$, which suggests that the metallic $\mathrm{Li}$ insertion between the crystalline $\mathrm{Li}_{x} \mathrm{MoO}_{2}$ domains causes the change in electronic structure.

It should be noted that this change in the electronic state of $\mathrm{Li}$ stored into a metal oxide differs from the interfacial Li-storage mechanism that has been used to explain the extra capacity of the transition metal oxide anode based on the conversion reaction mechanism $^{14}$. According to the interfacial storage mechanism, extra $\mathrm{Li}$ ions are stored on the side of $\mathrm{Li}_{2} \mathrm{O}$ at the interface between $\mathrm{Li}_{2} \mathrm{O}$ and transition metal, which are formed through the fully conversion reaction of the transition metal oxide ${ }^{14}$. However, the Li-storage mechanism proposed in the present work for ordered mesoporous $\mathrm{MoO}_{2}$ does not follow the conversion reaction of $\mathrm{MoO}_{2}$ into $\mathrm{Mo}$ and $\mathrm{Li}_{2} \mathrm{O}$, but rather retains the crystalline phases $\left(\mathrm{MoO}_{2}\right.$ and $\mathrm{Li}_{x} \mathrm{MoO}_{2}$ during the cycle), with metallic $\mathrm{Li}$ accommodated between the $\mathrm{Li}$-ion-intercalated $\mathrm{MoO}_{2}$ crystalline domains. This unexpected Li-storage mechanism for the extraordinarily high capacity of ordered mesoporous $\mathrm{MoO}_{2}$ can be attributed to the nanoscale pore-engineered structure, which offers a much higher surface area with a high metal oxide density. The thin $\mathrm{MoO}_{2}$ frameworks 
a
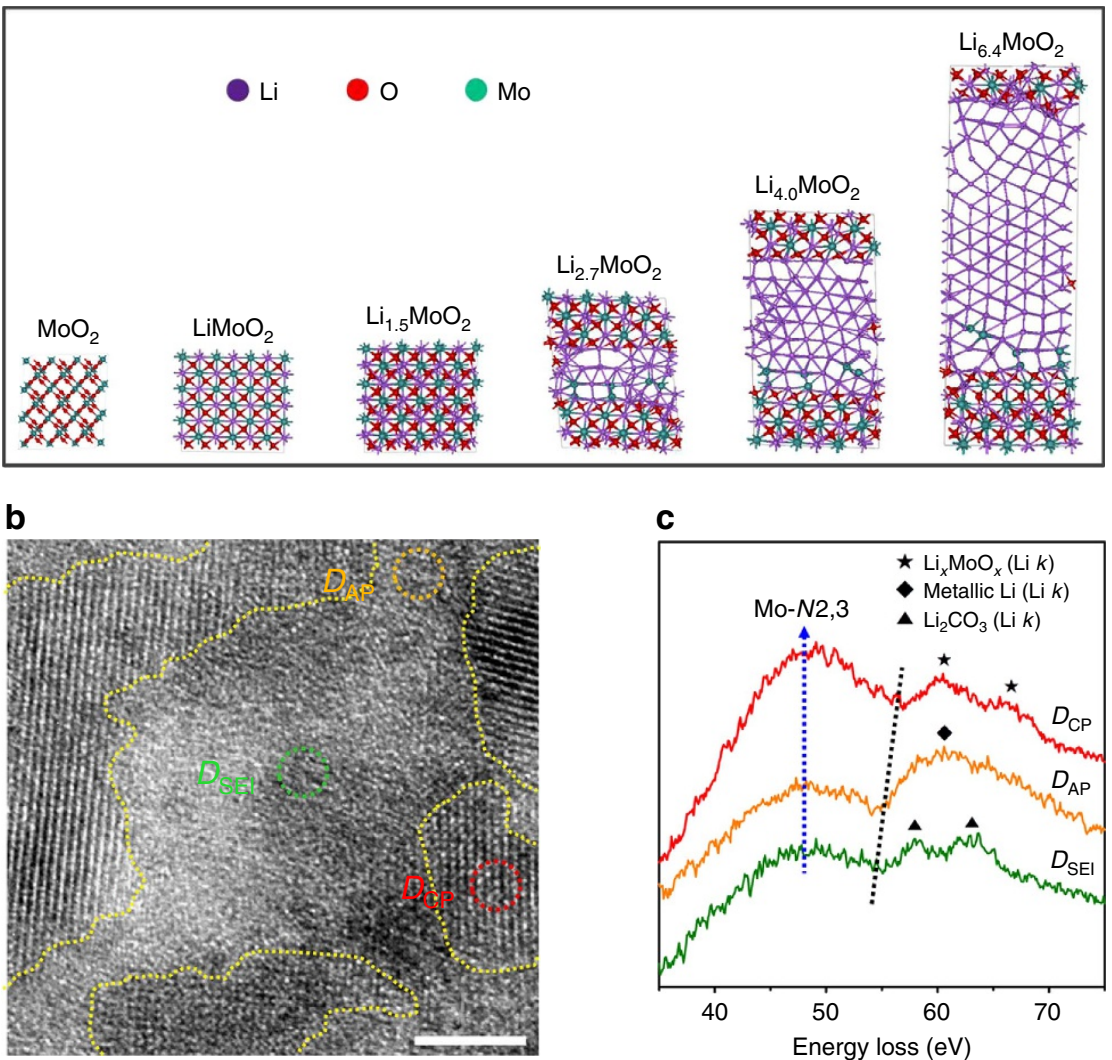

Figure 3 | DFT calculations and STEM-EELS spectra. (a) Snapshots of the ordered mesoporous $\mathrm{MoO}_{2}$ electrode with the increase of Li inserted, calculated by DFT, and (b) top-view HRTEM image taken from a fully lithiated ordered mesoporous $\mathrm{MoO}_{2}$, demonstrating the formation of three different phases: crystalline phase $\left(D_{\mathrm{CP}}\right)$, amorphous phase $\left(D_{\mathrm{AP}}\right)$ and SEI $\left(D_{\mathrm{SEI}}\right)$. Scale bar $=5 \mathrm{~nm}$. (c) STEM-EELS spectra taken from areas $D_{\mathrm{CP}}, D_{\mathrm{AP}}$ and $D_{\mathrm{SEI}}$ of the fully lithiated ordered mesoporous $\mathrm{MoO}_{2}$. Dotted lines represent the peak position of Mo $\mathrm{N}$ edge (blue) and the onset of Li K-edge (black).

$(\sim 7 \mathrm{~nm})$ greatly shorten the diffusion length for the Li ions, thus enabling the electrochemical reaction that cannot occur in the bulk analogue.

In order to obtain additional direct experimental evidences for the two-phase reaction model proposed here (formation of both Li-ion-intercalated $\mathrm{MoO}_{2}$ crystalline phase and metallic Li-rich phase) along with the change of the electronic state of $\mathrm{Li}$, we performed HRTEM and electron energy loss spectroscopy (EELS) studies on the fully lithiated and delithiated $\mathrm{MoO}_{2}$ electrode. The HRTEM image in Fig. $3 \mathrm{~b}$ clearly shows that there are three different phases formed in the fully lithiated $\mathrm{MoO}_{2}$, that is, crystalline phase $\left(D_{\mathrm{CP}}\right)$, amorphous phase $\left(D_{\mathrm{AP}}\right)$ and solid electrolyte interface (SEI) phase $\left(D_{\mathrm{SEI}}\right)$. The EELS data in scanning TEM (STEM) mode (STEM-EELS) taken at the crystalline area $\left(D_{\mathrm{CP}}\right)$ show that the $\mathrm{Li} K$-edge corresponds to $\mathrm{Li}_{x} \mathrm{MoO}_{2}$ (ref. 30), and this is closely relevant to the phase observed by ex situ XRD analyses, that is, Li-ion-intercalated $\mathrm{MoO}_{2}$ in Fig. 2a. However, STEM-EELS spectrum (Fig. 3c) taken at the amorphous area $\left(D_{\mathrm{AP}}\right)$ shows that energy loss near edge structures of Li species are different from those taken at other areas $\left(D_{\mathrm{CP}}\right.$ and $\left.D_{\mathrm{SEI}}\right)$ and corresponds to metallic $\mathrm{Li}^{31}$, implying that some of Li ions are accumulated as a form of metallic Li at the interface between nanosized crystalline $\mathrm{Li}_{x} \mathrm{MoO}_{2}$ domains. This $\mathrm{Li}$ storage as a metallic cluster resembles Li-storage mechanism of disordered carbon in the microspaces located at the edges of carbon clusters $32-35$.

In addition, as shown in Supplementary Fig. 12, the Z-contrast image and EELS spectra of $\mathrm{O} K$-edge taken at the crystalline phase $\left(D_{\mathrm{CP}}\right)$ and amorphous phase $\left(D_{\mathrm{AP}}\right)$ strongly support this finding because the area of amorphous phase $\left(D_{\mathrm{AP}}\right)$ shows darker contrast and lower oxygen intensity than the domain of the crystalline phase $\left(D_{\mathrm{CP}}\right)$. Another STEM-EELS result on the area of $D_{\text {SEI }}$ clearly shows a peak for $\mathrm{Li}_{2} \mathrm{CO}_{3}$ (Supplementary Fig. 13), which is one of the main components of SEI formed on the anode in the LIBs. As expected, the delithiated mesoporous $\mathrm{MoO}_{2}$ electrode does not contain any Li peaks, which suggests that it is reversibly returned to its initial state after the cycle (Supplementary Fig. 14). These EELS results strongly support the new reaction model of the ordered mesoporous $\mathrm{MoO}_{2}$ described in the present work.

Cycle performance and rate capability. Recently, we have developed an in operando small-angle X-ray scattering (SAXS) technique to investigate the nanostructural changes of ordered mesoporous electrode materials ${ }^{36}$. As shown in Fig. 4a,b and Supplementary Fig. 15, there is no significant changes in the in operando SAXS data of mesoporous $\mathrm{MoO}_{2}$ electrode during the lithiation and delithiation process $(\sim 20 \%$ reduction of peak intensity and $\sim 25 \%$ increase of net volume change). These small changes in nanostructural properties indicate that the present mesoporous $\mathrm{MoO}_{2}$ electrode seems to follow the intercalation mechanism with additional Li-storage sites rather than the conventional conversion mechanism ${ }^{36}$. Figure $4 \mathrm{c}-\mathrm{e}$ compares TEM images of the ordered mesoporous $\mathrm{MoO}_{2}$ structure during the first cycle. After complete lithiation, the diameter of the $\mathrm{MoO}_{2}$ frameworks increases from $\sim 7.8$ to $\sim 11.8 \mathrm{~nm}$. In addition to the diameter increase, there also should be a longitudinal volume 
a

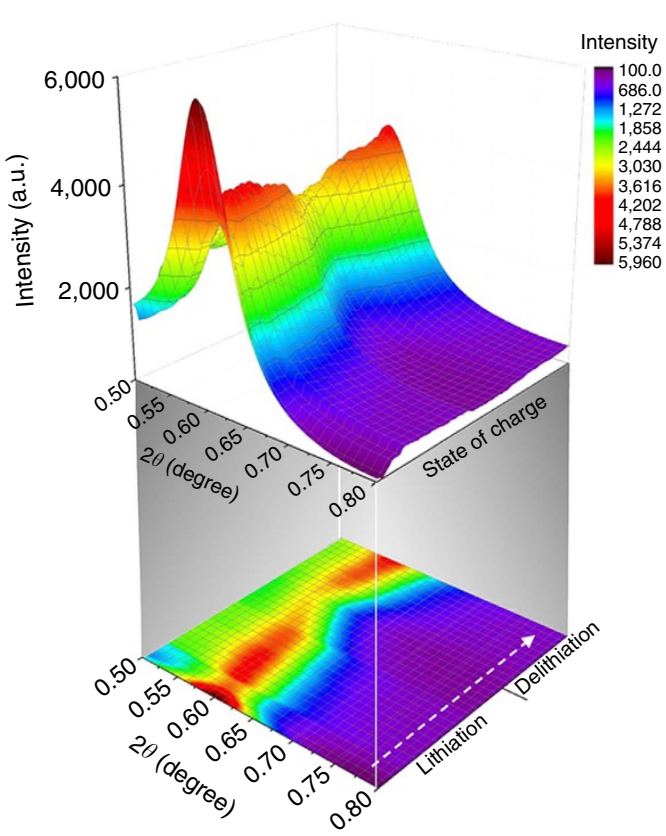

b

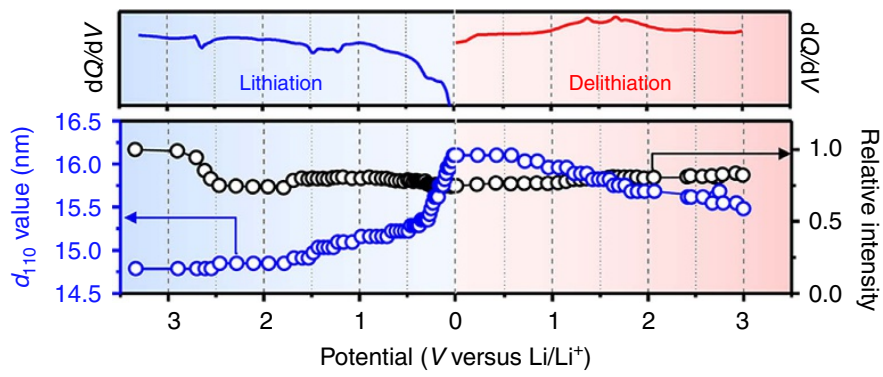

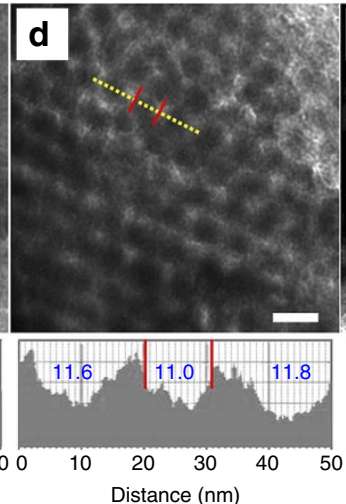

e

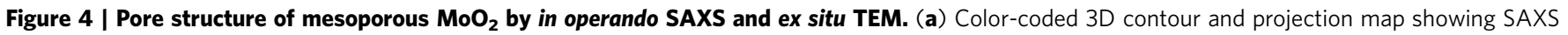

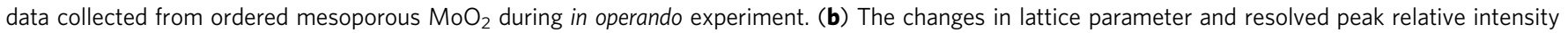
calculated from the (110) reflection with the corresponding dQ/dV plot. Representative TEM images and framework thickness of ordered mesoporous $\mathrm{MoO}_{2}$ electrodes: (c) pristine, (d) lithiated and (e) delithiated. Scale bars $=20 \mathrm{~nm}$.

expansion of $\mathrm{MoO}_{2}$ frameworks upon the lithiation (not experimentally observable). As shown by the ex situ XRD patterns and the DFT calculation on the lithiated $\mathrm{MoO}_{2}$ mesostructure (Figs $2 \mathrm{a}$ and $3 \mathrm{a}$ ), the volume expansion can be attributed to the formation of both the Li-ion-intercalated crystalline phase and the amorphous metallic Li-rich phase during the lithiation. However, it is reasonable that the expansion associated with $\mathrm{Li}$-ion intercalation is relatively smaller than that caused by the formation of the metallic Li-rich phase. This means that the volume expansion can be mainly attributed to the formation of the Li-rich phase, because the $d_{110}$ spacing of crystalline $\mathrm{MoO}_{2}$ in the XRD patterns and the HRTEM images of Fig. 2a,b expanded by $14.7 \%$ from the pristine state during the transformation from $\mathrm{MoO}_{2}$ to $\mathrm{Li}_{x} \mathrm{MoO}_{2}$. It should be noted that, despite these volume changes during the first cycle, the ordered mesoporous $\mathrm{MoO}_{2}$ retained its mesostructure even after complete lithiation and returned to the initial state after the complete delithiation (Fig. 4c-e). It is also important to note that this high capacity of ordered mesoporous $\mathrm{MoO}_{2}$ electrode shows a significant improvement in capacity retention compared with the bulk material. As shown in Fig. 1h, the present mesoporous $\mathrm{MoO}_{2}$ electrode retains $121.9 \%$ of the initial capacity after 50 cycles (from 1,308 to $1,594 \mathrm{mAh} \mathrm{g}^{-1}$ ).

Cyclic voltammetry (CV) of the ordered mesoporous $\mathrm{MoO}_{2}$ electrode reveals the same tendency of highly stable electrochemical storage and removal of $\mathrm{Li}$ up to 30 cycles (Supplementary Fig. 16). Li-storage capacity of the ordered mesoporous $\mathrm{MoO}_{2}$ electrode shows the continuous increase with an increase of cycle numbers up to 20 cycles, and then reached the steady-state value (Supplementary Fig. 16b). Considering that this newly evolved couple of CV peaks could not be reported by other reports ever, the reduction $(\sim 0.2 \mathrm{~V})$ and oxidation peak $(\sim 2.5 \mathrm{~V})$, which can be also found at the differential capacity plots of the ordered mesoporous $\mathrm{MoO}_{2}$ electrode (Supplementary Fig. 17), would be associated with Li-storage reaction mechanism to account for high capacity of the ordered mesoporous $\mathrm{MoO}_{2}$ electrode presented here. It should be also noted that the rectangular $\mathrm{CV}$ profiles took shape with an increase of $\mathrm{CV}$ cycle numbers, indicating that $\mathrm{Li}$-storage reaction in the ordered mesoporous $\mathrm{MoO}_{2}$ might resemble the electrochemical reaction observed in the supercapacitors rather than in the typical rechargeable batteries. Considering that under-potential deposition of metal ions is one of the typical super-capacitive electrochemical reactions, the rectangular shape of CV profiles observed in the mesoporous $\mathrm{MoO}_{2}$ electrode might be a circumstantial evidence to prove the storage of $\mathrm{Li}$ as a metallic phase in the ordered mesoporous $\mathrm{MoO}_{2}$ electrode.

Mo K-edge EXAFS spectra for $\mathrm{MoO}_{2}$ during electrochemical cycles are shown in Supplementary Fig. 18. We found that Mo-O peak from oxide phase is still major contribution in EXAFS spectra during cycles, even though the peak intensities are gradually reduced due to the cycle-induced structural disorder. It is notable that Mo-Mo peak from Mo metallic phase does not appear even after 10 cycles, clearly confirming no possibility to have the conversion reaction in $\mathrm{MoO}_{2}$ electrode.

Rate capability is also very important for electrode materials in addition to Li-storage capacity. We modified the mesostructure of the ordered mesoporous $\mathrm{MoO}_{2}$ by reducing the wall thickness from 7.9 to $7.0 \mathrm{~nm}$ and 5.5 to $4.0 \mathrm{~nm}$ (but for similar mesopore size of $\sim 18 \mathrm{~nm}$, see Supplementary Figs 19-22 and Supplementary Tables 2 and 3), in order to examine the effects of framework thicknesses on the rate capability of mesoporous $\mathrm{MoO}_{2}$. As shown in Supplementary Fig. 23, the rate capability was slightly enhanced by reducing the framework thickness of the mesoporous $\mathrm{MoO}_{2}$ materials from 7.0 to $5.8 \mathrm{~nm}$, which is probably by shortening the diffusion length for $\mathrm{Li}$ ion in the $\mathrm{MoO}_{2}$ framework. However, neither further reduction $(5.1 \mathrm{~nm})$ nor increase $(7.8 \mathrm{~nm})$ gives a positive effect on the rate capability. Research is underway to find the optimized mesopore size and 


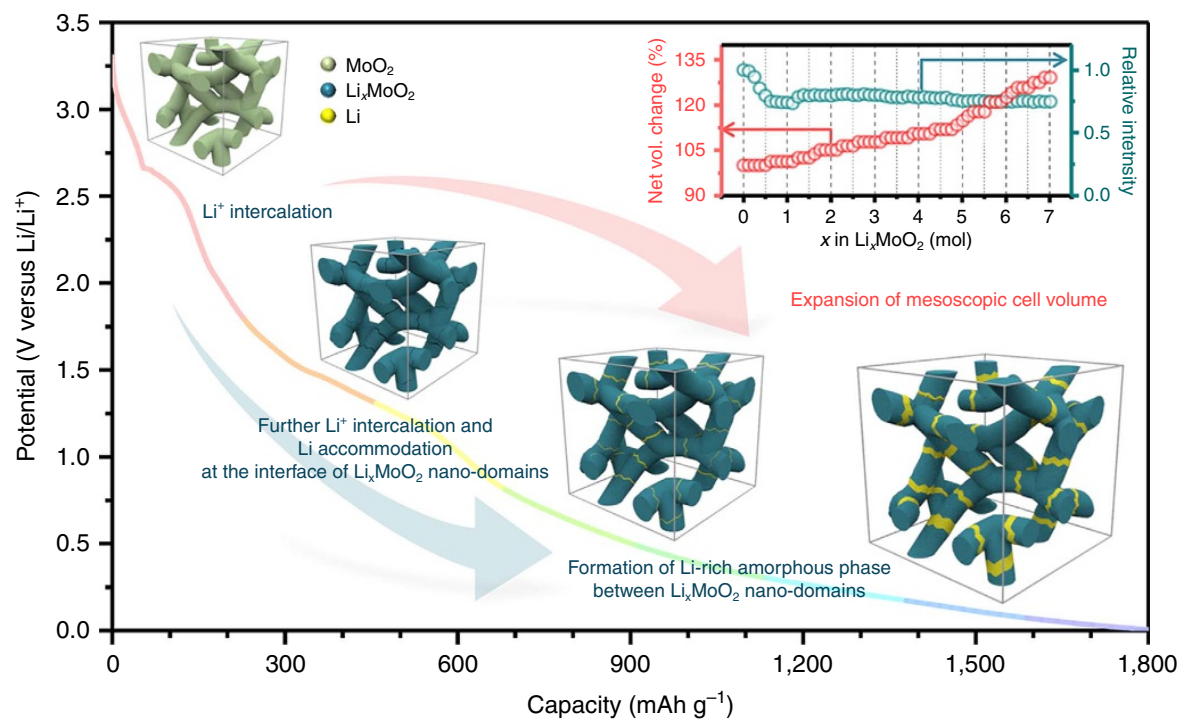

Figure 5 | Schematic diagram of the reaction pathways and mesoscale morphology. Schematic diagram of the reaction pathways and the resulting products of ordered mesoporous $\mathrm{MoO}_{2}$ with respect to the amount of $\mathrm{Li}$ ion inserted.

framework thickness necessary to obtain the best electrochemical performance.

\section{Discussion}

We report a high-capacity Li-storage material, ordered mesoporous $\mathrm{MoO}_{2}$, with a capacity that exceeds the storage capacity predicted by the conventional Li-storage mechanism such as $\mathrm{Li}$ intercalation and/or conversion reaction of transition metal oxide. We suggest a Li-storage mechanism consisting of a Li-ion intercalation reaction and the formation of a metallic Li-rich phase between the Li-ion-intercalated $\mathrm{MoO}_{2}$ phase, based on first-principle calculations on the electronic structure of lithiated ordered mesoporous $\mathrm{MoO}_{2}$, along with DFT calculations, in situ X-ray absorption spectroscopies and HRTEM analyses combined with EELS studies of the reacted ordered mesoporous $\mathrm{MoO}_{2}$ (Fig. 5). In addition to the high capacity and excellent cycle performance of ordered mesoporous $\mathrm{MoO}_{2}$, the proposed Li-storage mechanism clearly shows how the nanoscale engineering impacts the associated physicochemical properties of the material for electrochemical mass storage applications. The present results enable a structural and electronic configuration that is, in a sense, a hybrid between the Li-intercalated compound anode and the metallic Li anode, with the inherent safety features of the former and a high power density approaching to that of the latter. The results further provide a more complete understanding of possible Li-storage mechanisms for transition metal oxides, and thus make possible the further advancement of ultrahigh capacity anode materials for Li rechargeable batteries.

\section{Methods}

Mesoporous silica template. In the present work, mesoporous silica, KIT-6, with cubic Ia3d mesostructure was used as the silica template for preparing mesoporous $\mathrm{MoO}_{2}$ materials. Pluronic triblock copolymer $\mathrm{P} 123\left(\mathrm{EO}_{20} \mathrm{PO}_{70} \mathrm{EO}_{20}, \mathrm{MW}=5,800\right)$ was utilized as the structure-directing agent for synthesis of KIT-6. Typically, $90.0 \mathrm{~g}$ of P123 was dissolved in a mixture of $3,255 \mathrm{~g}$ of distilled water, $90 \mathrm{~g}$ of $1-\mathrm{BuOH}$ (99.7 wt \%, Aldrich) and $177 \mathrm{~g}$ of $c-\mathrm{HCl}\left(35 \mathrm{wt} \%\right.$, Aldrich). After stirring at $35^{\circ} \mathrm{C}$ for $10 \mathrm{~min}, 193.5 \mathrm{~g}$ of tetraethylorthosilicate (98 wt\%, Aldrich) was added to this solution under vigorous stirring. The resulting mixture was stirred for $24 \mathrm{~h}$ at $35^{\circ} \mathrm{C}$ and subsequently kept in static condition at $100^{\circ} \mathrm{C}$ for $24 \mathrm{~h}$ in an oven. The solid product was filtered, washed with double distilled water and dried at $100^{\circ} \mathrm{C}$ overnight. The white powder, thus obtained, was washed with $\mathrm{EtOH}$, dried at $80^{\circ} \mathrm{C}$ for $12 \mathrm{~h}$, and finally calcined under static air conditions at $550^{\circ} \mathrm{C}$ for $3 \mathrm{~h}$ in order to remove the structure-directing agent. Mesopore size of the KIT- 6 template calculated by Barrett-Joyner-Halenda method was $7.1 \mathrm{~nm}$. KIT-6 materials with different pore sizes (5.1, 5.8 and $7.9 \mathrm{~nm}$; see Supplementary Table 2 and Supplementary Fig. 19) were also synthesized using the above method, except for the hydrothermal treatment at 60,80 and $140{ }^{\circ} \mathrm{C}$, respectively.

Highly ordered mesoporous $\mathbf{M o O}_{\mathbf{2}}$ materials. The mesoporous $\mathrm{MoO}_{2}$ materials were synthesized by the nano-replication method using the KIT-6 as the mesoporous silica templates. An amount of $6.49 \mathrm{~g}$ of ammonium molybdate tetrahydrate $\left(\left(\mathrm{NH}_{4}\right)_{6} \mathrm{Mo}_{7} \mathrm{O}_{24} \bullet 4 \mathrm{H}_{2} \mathrm{O}\right.$, Aldrich) was dissolved in $8.4 \mathrm{~g}$ of distilled water. This precursor solution was infiltrated into $10.0 \mathrm{~g}$ of the calcined KIT- 6 template by an incipient wetness method. After drying the composite at $80^{\circ} \mathrm{C}$ for $24 \mathrm{~h}$, the resulting material was heated to $500^{\circ} \mathrm{C}$ under nitrogen atmosphere for $5 \mathrm{~h}$ for crystallization. After the heat treatment, the silica template was removed from the composite by a wet-etching process using a $20 \mathrm{wt} \%$ hydrofluoric acid (HF) solution. The resulting solid product was washed with distilled water and acetone several times, and then dried at $80^{\circ} \mathrm{C}$ overnight in an oven. The mesoporous $\mathrm{MoO}_{2}$ materials, synthesized from the KIT- 6 with different pore sizes, are denoted as meso$\mathrm{MoO}_{2}-x$ (where $x$ means the synthesis temperature of KIT- 6 templates). The mesoporous $\mathrm{MoO}_{2}$ materials with surface area of 39 and $76 \mathrm{~m}^{2} \mathrm{~g}^{-1}$ were prepared by following the same synthesis method with the above procedure, except for the precursor infiltration conditions. The precursor solutions were prepared by dissolving $20.7 \mathrm{~g}$ of $\left(\mathrm{NH}_{4}\right)_{6} \mathrm{Mo}_{7} \mathrm{O}_{24} \bullet 4 \mathrm{H}_{2} \mathrm{O}$ in $15 \mathrm{~g}$ of distilled water and $8.11 \mathrm{~g}$ of $\left(\mathrm{NH}_{4}\right)_{6} \mathrm{Mo}_{7} \mathrm{O}_{24} \bullet 4 \mathrm{H}_{2} \mathrm{O}$ in $10.5 \mathrm{~g}$ of distilled water for the mesoporous $\mathrm{MoO}_{2}$ with surface areas of 39 and $76 \mathrm{~m}^{2} \mathrm{~g}^{-1}$, respectively. Two mixed $\mathrm{MoO}_{2}$ electrodes was simply prepared by physically mixing the bulk $\mathrm{MoO}_{2}\left(\right.$ Aldrich, $S_{\mathrm{BET}}=0.23 \mathrm{~m}^{2} \mathrm{~g}^{-1}$ ) and the highly ordered mesoporous $\mathrm{MoO}_{2}$ (this work, $S_{\mathrm{BET}}=115 \mathrm{~m}^{2} \mathrm{~g}^{-1}$ ). The weight ratios between the bulk and mesoporous $\mathrm{MoO}_{2}$ materials were 1:3 and 3:2 for the mixtures with surface areas of $21 \mathrm{~m}^{2} \mathrm{~g}^{-1}$ and $53 \mathrm{~m}^{2} \mathrm{~g}^{-1}$, respectively. The mixed $\mathrm{MoO}_{2}$ materials were thoroughly hand-mixed with mortar and pestle.

Characterization. XRD patterns for the mesoporous silica and mesoporous $\mathrm{MoO}_{2}$ powder were obtained using a Rigaku D/MAX-2200 Ultima equipped with $\mathrm{Cu} \mathrm{K} \alpha$ radiation at $30 \mathrm{kV}$ and $40 \mathrm{~mA}$. Ex situ XRD patterns of electrodes during the cycles were recorded in reflection mode using an X'Pert PRO equipped with $\mathrm{Cu} \mathrm{K} \alpha$ radiation at $40 \mathrm{kV}$ and $40 \mathrm{~mA}$ in the $20-60^{\circ}(2 \theta)$ angular range. In situ XANES and EXAFS spectra were collected on beamline $10 \mathrm{C}$ at Pohang Accelerator Laboratory. Energy calibration was carried out using the first inflection point of the spectrum of Mo metal foil as a reference (that is, Mo $K$-edge $=20,000 \mathrm{eV}$ ). Reference spectra were simultaneously collected for each in situ spectrum using Mo metal foil. In operando SAXS experiments were carried out using BL 9 A U-SAXS beamline (Pohang Accelerator Laboratory) with a two-dimensional (2D) CCD detector (Rayonix SX165, USA) that was positioned $2 \mathrm{~m}$ away from the sample, which measured scattering in the $2 \theta$ range of $0.3-2.5(\lambda=1.54 \AA)$. The size of the focused beam was $300 \mu \mathrm{m}$ in diameter and the energy of the beam was $11 \mathrm{keV}$. The $2 \mathrm{D}$ patterns of the mesoporous samples during electrochemical cycling were recorded with a 1-s exposure time and $8 \mathrm{~s}$ detector readout time. The $2 \mathrm{D}$ patterns were scanned with the FIT2D software package to obtain the 1D patterns in the form of the intensity versus $2 \theta$. The storage ring was operated at $3.0 \mathrm{GeV}$ with a ring current of $300 \mathrm{~mA}$. SEM images were taken using a LEO Supra 55 field-emission SEM operating at an accelerating voltage of $15 \mathrm{kV}$. Ultra-high-resolution SEM images were obtained using a Hitachi UHR S 5500 FE-SEM operating at $30 \mathrm{kV}$. 
The main instruments we used in this study for microscopy were an aberrationcorrected FEI TITAN field-emission TEM and a JEOL JEM 3010 TEM operated at an accelerating voltage of $300 \mathrm{kV}$. EELS analysis was performed in STEM mode using the field-emission TEM (TITAN) equipped with a high-resolution Gatan Tridieum 865ER imaging spectrometer. Because the $\mathrm{MoO}_{2}$ electrodes during lithiation and delithiation were sensitive to air and moisture, all the sampling process was carried out in an argon-filled glove box. For TEM observations, all the specimens were moved to the instruments using argon-filled plastic tubes and carefully transferred to the instruments within $10 \mathrm{~s}$ in order to minimize the air-contacting time. $\mathrm{N}_{2}$ adsorption-desorption isotherms were collected on a Micromeritics Tristar system at liquid $\mathrm{N}_{2}$ temperature. All of the samples were completely dried under vacuum at $100^{\circ} \mathrm{C}$ for $24 \mathrm{~h}$ before the measurement. The specific BET (Brunauer-Emmett-Teller) surface areas were calculated from the adsorption branches in the range of relative pressure $\left(p / p_{0}\right)=0.05-0.20$. The pore size distribution curves were obtained by the Barrett-Joyner-Halenda method on the basis of the adsorption branches. Total pore volumes were measured at $p / p_{0}=0.99$.

Electrochemistry. Electrodes were prepared by coating the slurries that contain the mesoporous $\mathrm{MoO}_{2}$ material as the active material powder, carbon black (Super-P, MMM) as the conducting agent and polyamideimide (Torlon 4,000 T, Solvay) as the binder in the weight ratio of 70:15:15 in N-methyl-2-pyrrolidone (Aldrich) solvent to produce an electrode slurry. The slurry was coated onto a $\mathrm{Cu}$ foil current collector using a Doctor-Blade technique. After the coating procedure, the electrodes were pressed and dried for $2 \mathrm{~h}$ at $200^{\circ} \mathrm{C}$ under vacuum conditions. The electrodes thus obtained were cut into disks (12 $\mathrm{mm}$ in diameter). Coin-type cells (CR2016) were assembled in a dry room using Celgard 3,501 as the separator and Li foil as the counter and reference electrodes. On the basis of the current density of $0.1 \mathrm{C}$ $\left(=80 \mathrm{mAh} \mathrm{g}^{-1}\right)$, all cells were tested at within a fixed voltage window $(0.001-3.0 \mathrm{~V})$ using a battery cycle tester (TOSCAT 4,000 series, Tokyo, Japan).

Computational method. The first-principle calculations based on the DFT was performed using the VASP code. Initial structure of $\mathrm{MoO}_{2}$ is the $3 \times 3 \times 1$ supercells including $36 \mathrm{Mo}$ and $72 \mathrm{O}$ atoms. The plane-wave cutoff energy was chosen to be $400 \mathrm{eV}$ and appropriate $k$-points were chosen to ensure that the total energies are converged within a few $\mathrm{meV}$. The exchange-correlation interactions between electrons were described by the generalized gradient approximation, and projector-augmented wave potentials were used for the description of ion-electron interactions. We used the conjugate gradient method for geometry optimizations, and the optimization procedure was truncated when the residual forces for the relaxed atoms were $<0.03 \mathrm{eV}$ per $\AA$. In the calculation of $\mathrm{Li}_{x} \mathrm{MoO}_{2}$, $\mathrm{Li}$ atoms were inserted to the position of the energetically most stable site. During the lithiation, the atomic position and cell structures are fully relaxed simultaneously.

\section{References}

1. Nishi, Y. The development of lithium ion secondary batteries. Chem. Rec. 1, 406-413 (2001).

2. Tarascon, J.-M. \& Armand, M. Issues and challenges facing rechargeable lithium battery. Nature 414, 359-367 (2001).

3. Ellis, B. L., Lee, K. T. \& Nazar, L. F. Positive electrode materials for Li-ion and Li-batteries. Chem. Mater. 22, 691-714 (2010).

4. Jeong, G., Kim, Y.-U., Kim, H., Kim, Y.-J. \& Sohn, H.-J. Prospective materials and applications for Li secondary batteries. Energ. Environ. Sci. 4, 1986-2002 (2011).

5. Lee, K. T. \& Cho, J. Roles of nanosize in lithium reactive nanomaterials for lithium ion batteries. Nano Today 6, 28-41 (2011).

6. Huang, J. Y. et al. In situ observation of the electrochemical lithiation of a single $\mathrm{SnO}_{2}$ nanowire electrode. Science 330, 1515-1520 (2010).

7. Chan, C. K. et al. High-performance lithium battery anodes using silicon nanowires. Nat. Nanotechnol. 3, 31-35 (2008).

8. Park, C.-M., Kim, J.-H., Kim, H. \& Sohn, H.-J. Li-alloy based anode materials for Li secondary batteries. Chem. Soc. Rev. 39, 3115-3141 (2010).

9. Poizot, P., Laruelle, S., Grugeon, S., Dupont, L. \& Tarascon, J.-M. Nano-sized transition-metal oxides as negative-electrode materials for lithium-ion batteries. Nature 407, 496-499 (2000).

10. Lee, Y. J. et al. Fabricating genetically engineered high-power lithium-ion batteries using multiple virus genes. Science 324, 1051-1055 (2009).

11. Armand, M. \& Tarascon, J.-M. Building better batteries. Nature 451, 652-657 (2008).

12. Grugeon, S. et al. Particle size effects on the electrochemical performance of copoer oxides toward lithium. J. Electochem. Soc. 148, A285-A292 (2001).

13. Li, H., Richter, G. \& Maier, J. Reversible formation and decomposition of LiF clusters using transition metal fluorides an precursors and their application in rechargeable Li batteries. Adv. Mater. 15, 736-739 (2003).

14. Jamnik, J. \& Maier, J. Nanocrystallinity effects in lithium battery materials. Phys. Chem. Chem. Phys. 5, 5215-5220 (2003).

15. Hu, Y.-Y. et al. Origin of additional capacities in metal oxide lithium-ion battery electrodes. Nat. Mater. 12, 1130 (2013).
16. Cheng, F., Liang, J., Tao, Z. \& Chen, J. Functional materials for rechargeable batteries. Adv. Mater. 23, 1695-1715 (2011).

17. Bruce, P. G., Scrosati, B. \& Tarascon, J.-M. Nanomaterials for rechargeable lithium batteries. Angew. Chem. Int. Ed. 47, 2930-2946 (2008).

18. Liu, C., Li, F., Ma, L.-P. \& Cheng, H.-M. Advanced materials for energy storage. Adv. Mater. 22, E28-E62 (2010).

19. Kresge, C. T., Leonowicz, M. E., Roth, W. J., Vartuli, J. C. \& Beck, J. S. Ordered mesoporous molecular sieves synthesized by a liquid-crystal template mechanism. Nature 359, 710-712 (1992).

20. Zhao, D. et al. Triblock copolymer syntheses of mesoporous silica with periodic 50 to 300 angstrom pores. Science 279, 548-552 (1998).

21. Joo, S. H. et al. Ordered nanoporous arrays of carbon supporting high dispersions of platinum nanoparticles. Nature 412, 169-172 (2001).

22. Lee, H. I. et al. Spontaneous phase separation mediated synthesis of 3D mesoporous carbon with controllable cage and window size. Adv. Mater. 23, 2357-2361 (2011).

23. Chang, H., Joo, S. H. \& Pak, C. Synthesis and characterization of mesoporous carbon for fuel cell applications. J. Mater. Chem. 17, 3078-3088 (2007).

24. Yue, W. et al. Syntheses, Li insertion and photoactivity of mesoporous crystalline $\mathrm{TiO}_{2}$. Adv. Func. Mater. 19, 2826-2833 (2009).

25. Ren, Y., Jardwick, L. J. \& Bruce, P. G. Lithium intercalation into mesoporous anatase with an ordered 3D pore structure. Adv. Mater. 49, 2570-2574 (2010).

26. Ren, Y., Armstrong, A. R., Jiao, F. \& Bruce, P. G. Influence of size on the rate of mesoporous electrodes for lithium batteries. J. Am. Chem. Soc. 132, 996-1004 (2010).

27. Shi, Y. et al. Ordered mesoporous metallic $\mathrm{MoO}_{2}$ materials with highly reversible lithium storage capacity. Nano Lett. 9, 4215-4220 (2009).

28. Sohn, J. K. et al. Nano-propping effect of residual silicas on reversible lithium storage over highly ordered mesoporous $\mathrm{SnO}_{2}$ materials. J. Mater. Chem. 19, 6727-6732 (2009).

29. Chen, C., Ding, N., Wang, L., Yu, Y. \& Lieberwirth, I. Some new facts on electrochemical reaction mechanism for transition metal oxide electrodes. J. Power Sources 189, 552-556 (2009).

30. Cosandey, F. in Microscopy: Science, Technology, Applications and Education (eds Méndez-Vilas, A. \& Díaz, J.) Vol. 3, 1662-1666 (Formatex, 2010).

31. Hightower, A., Ahn, C. C., Fultz, B. \& Rez, P. Electron energy-loss spectrometry on lithiated graphite. Appl. Phys. Lett. 77, 238-240 (2000).

32. Mochida, I., Ku, C.-H. \& Korai, Y. Anodic performance and insertion mechanism of hard carbons prepared from synthetic isotropic pitches. Carbon N. Y. 39, 399-410 (2001).

33. Dahn, J. R., Zheng, T., Liu, Y. \& Xue, J. S. Mechanisms for lithium insertion in carbonaceous materials. Science 270, 590-593 (1995).

34. Mabuchi, A., Tokumitsu, K., Fujimoto, H. \& Kasuh, T. Charge-discharge characteristics of the mesocarbon miocrobeads heat-treated at different temperatures. J. Electrochem. Soc. 142, 1041-1046 (1995).

35. Mochida, I., Ku, C.-H., Yoon, S. H. \& Korai, Y. Anodic performance and mechanism of mesophase-pitch-derived carbons in lithium ion batteries. J. Power Sources 75, 214-222 (1998).

36. Park, G. O. et al. In operando monitoring of the pore dynamics in ordered mesoporous electrode materials by small angle X-ray scattering. ACS Nano $\mathbf{9}$, 5470-5477 (2015).

\section{Acknowledgements}

This work was supported by Samsung Research Funding Center for Future Technology (SRFC-MA1401-03). We also thank partial supports obtained from the Energy Efficiency and Resources Core Technology Program of the Korea Institute of Energy Technology Evaluation and Planning (KETEP), which granted financial resource from the Ministry of Trade, Industry and Energy, Republic of Korea (no. 20132020000260), the research fund of Hanyang University (HY-2012-T), the US National Science Foundation (DMR 0805148) and the National Research Foundation of Korea (NRF-2010-C1AAA001-20100029065 and the Mid-Career Researcher Program No. 2012R1A2A2A01010011).

\section{Author contributions}

J.M.K., W.-S.Y., C.P., H.K. and G.D.S. conceived, designed and coordinated the study. H.S.L. carried out theoretical calculations. J.K.S., G.O.P., J.Y., E.P., G.S.P., S.S.K., M.J., J.-M.C., H.C. and S.D. performed the experiment and acquired the data. J.M.K., H.S.L., J.K.S., W.-S.Y, C.P., H.K. and G.D.S. wrote the paper. All the authors participated in analysis of the experimental data and discussions of the results, as well as preparing the paper.

\section{Additional information}

Supplementary Information accompanies this paper at http://www.nature.com/ naturecommunications

Competing financial interests: The authors declare no competing financial interests. 
Reprints and permission information is available online at http://npg.nature.com/ reprintsandpermissions/

How to cite this article: Shon, J. K. et al. Discovery of abnormal lithium-storage sites in molybdenum dioxide electrodes. Nat. Commun. 7:11049 doi: 10.1038/ncomms11049 (2016). (c) (i) This work is licensed under a Creative Commons Attribution 4.0 International License. The images or other third party material in this article are included in the article's Creative Commons license, unless indicated otherwise in the credit line; if the material is not included under the Creative Commons license, users will need to obtain permission from the license holder to reproduce the material. To view a copy of this license, visit http://creativecommons.org/licenses/by/4.0/ 